\title{
Enamel Tissue Engineering
}

\author{
Masaki J. Honda ${ }^{1}$ and Ken-ichiro Hata ${ }^{2}$ \\ ${ }^{1}$ Department of Anatomy, Nihon University School of Dentistry \\ ${ }^{2 J a p a n}$ Tissue Engineering, Co. Ltd.
}

\section{Short description of the book chapter}

Dental scientists are eagerly embracing regenerative medicine using tissue engineering technology. Enamel, one component of teeth, is the hardest tissue in the body. It cannot regenerate by itself, because it is formed by a layer of ameloblasts that is lost by the time the tooth crown has completely formed. Although the enamel is spent during lifetime, it is vulnerable to wear, damage, and decay. For these reasons, the development of a technique that produces artificially-grown enamel using culture and transplantation techniques is strongly desired. In this chapter we report a new technique for culturing enamel organ epithelial cells that have the capacity to produce enamel.

After completion of the formation of the tooth crown, which is composed of an enamel-dentin complex, tooth root formation begins. Generally, no new ameloblasts or enamel is generated from the enamel organ epithelial cells after the tooth root is formed. Epithelial cell rests of Malassez, derived from Hertwig's epithelial root sheath fragments, are located in the periodontal ligament, and recently we reported that these cells are also capable of enamel production using the same technique.

Dental epithelial cells including enamel organ epithelial cells and epithelial cell rests of Malassez can continue to proliferate when they are subcultured on top of feeder layer cells. These subcultured cells were placed onto collagen sponge scaffolds along with dental pulp cells and the constructs were transferred into the abdominal cavities of rats. When removed after 4 weeks, enamel production was observed in the scaffolds. The key finding of this study is that even after multiple divisions, the cells retained the capacity to produce enamel. Now that dental epithelial cells can be generated by a culture and transplantation system, the next step will be to combine the tissue-engineered enamel with the injured enamel in original teeth.

\section{Abbreviations}

EOE, enamel organ epithelial; ERM, epithelial cell rests of Malassez; HERS, Hertwig's epithelial root sheath; KLK4, kallikrein-4; MMP-20, enamelysin; PDL, periodontal ligament 


\section{Introduction}

One purpose of studying the development and structure of enamel is to understand how it responds to enamel loss caused by caries or fractures. One of frequent dental disease is dental caries which is a specific infectious disease of the teeth that results in localized dissolution and destruction of the calcified enamel and dentin $(1,2)$. Enamel is the hardest tissue in the body and it does not regenerate because the cells that synthesize the enamel matrix are lost during tooth eruption. To replace enamel, dentistry has formulated artificial materials that mimic the hardness of enamel but replacing enamel with artificial substitutes may not be the most appropriate therapy. The establishment of a novel therapy to engineer natural enamel would provide an important approach to repair enamel loss.

Recently, tissue engineering therapy for tooth replacement has been addressed using various strategies and all such attempts share a common feature, which is that odontogenic capacity is necessary to generate a tooth structure. The first successful report described tooth structures such as the enamel-dentin complex generated in vivo by seeding dissociated odontogenic cells from a 6-month porcine third molar onto polyglycolic acid fiber mesh (3). The data suggested the presence of epithelial and mesenchymal progenitor/stem cells in the early stages of crown formation in the developing tooth. Furthermore, these results indicated a high likelihood of developing a technique to generate enamel. Importantly, this successful attempt provided one novel strategy to create natural enamel. In this chapter we describe our strategy to generate enamel using tissue engineering technology. However, many issues still remain to be resolved before we can apply the method to clinical practice.

So why is it difficult to generate enamel? There are two big obstacles. Firstly, no one has yet achieved successful tooth regeneration using subcultured odontogenic cells. One of the reasons is that it is difficult to expand the ameloblast-lineage cells that are capable of secreting amelogenin which is a constituent of enamel. Recently, dental tissues such as the periodontal ligament (PDL), dental papilla and dental follicle have been identified as easily accessible sources of undifferentiated cells. Dental mesenchymal stem cells could be feasible tools for dental tissue engineering. However, dental epithelial stem cells have not been discovered in teeth. Secondly, how can ameloblasts be harvested if they disappear when tooth-crown formation is completed? Practically this approach is obviously limited by the very small number of cells that can be obtained.

This article mainly reviews the novel therapy developed to generate natural enamel using a subculture and transplantation system, and the new cell sources for enamel regeneration in light of the two main difficulties mentioned above.

\section{Tooth development}

Tooth development is regulated by inductive signals between ectoderm-derived epithelium and neural crest-derived ectomesenchyme $(4,5)$. Teeth are initiated with an invagination from the oral epithelium. The oral epithelium at this stage has been shown to have the potential to instruct tooth development. Thereafter, the horseshoe-shaped dental lamina generates the future dental arches as the cap stage. During the cap and bell stages, transient signaling centers are generated in the epithelium as primary and secondary enamel knots. Secondary enamel knots appear at the site of the future cusp tips and contribute to the shaping of the tooth crown at the bell stage. At the crown formation stage, the 
enamel-secreting ameloblasts and dentin-secreting odontoblasts differentiate from the inner enamel epithelium and dental pulp, respectivelyand dental pulp which being derived from the dental papilla, respectively.. Both ameloblasts and odontoblasts are subsequently involved in the formation of tooth crowns, which consist of the enamel-dentin complex.

\section{Enamel}

Enamel, the most highly mineralized dental tissue, is composed of crystalline calcium phosphate and is approximately $96 \%$ mineral with the remaining $4 \%$ consisting of organic components and water. The basic micro-structural unit of enamel is an enamel rod, which is tightly packed and adherent to other enamel rods. The interwoven architecture of enamel rods contributes to both its strength and resistance to fracture.

Enamel is generated by ameloblasts which are epithelial cells derived from the enamel organ in the developing tooth, which covers the dentin-pulp complex. Differentiation of epithelial cells towards ameloblasts is regulated by an interaction between the epithelial and mesenchymal cells. The major difference between enamel and mucosa is the absence of any epithelial response because the cells that form enamel are lost at the time of tooth eruption, which means that enamel is neither replaceable nor repairable after eruption.

Amelogenin is produced by ameloblasts and is the most abundant protein within the enamel, accounting for more than $90 \%$ of the total enamel-related proteins. Studies in amelogenin knockout mice showed that amelogenin plays an important role in enamel biomineralization $(6,7)$, and while ameloblast differentiation is relatively normal in these mice, an abnormally thin enamel layer is formed (8). Amelogenins are essential for the formation of hydroxyapatite in enamel (9), and they are also recognized as a key factor in controlling the orientation and elongated growth of enamel rods during the mineralization process (10). In addition to amelogenin, the developing enamel is composed of several structural proteins such as ameloblastin (sheathlin/amelin), enamelin, and tuftelin. They are eventually degraded by the action of proteinases such as enamelysin (MMP-20) and kallikrein 4 (KLK4) (formerly known as enamel matrix serine proteinase 1). Ameloblastin is the most abundant non-amelogenin enamel-specific glycoprotein (11-13), and functions as a cell adhesion molecule for ameloblasts, but not for dental epithelial cells (14). Ameloblastin expression in ameloblasts peaks at the secretory stage and diminishes at the maturation stage, and maintenance of normal levels of ameloblastin in enamel formation is important because overexpression of ameloblastin in ameloblasts impairs the enamel structures (15). Furthermore, although dental epithelial cells can differentiate into ameloblasts in ameloblastin knockout mice, the ameloblasts detach from the matrix surface at the secretory stage and lose polarity (14), suggesting that ameloblastin is essential for maintaining normal ameloblast differentiation and attachment to the enamel matrix. In a recent study however, amelogenin and ameloblastin double knockout mice still showed a very thin layer of enamel, which was due to the presence of enamelin which was still expressed in the teeth of these double knockout mice. The enamelin gene has also been implicated in human amelogenesis imperfecta. Enamelin knockout mice do not form normal enamel, because of the lack of mineralization at the secretory surface of the ameloblasts (16), which suggests that enamelin is also necessary for enamel formation. 


\section{Enamel organ epithelial cell culture}

Tissue engineering protocols generally involve the proliferation of tissue-specific stem cells in vitro that support development of a particular cellular phenotype (17). These cells are grown under specific culture conditions and can be transplanted into the body, in order to generate new tissue or organs (18). Recently, dental pulp stem cells isolated from post-natal pulp (19) and from deciduous tooth pulp (20) have been described. Dental mesenchymal stem cells have been highlighted for their ability to form dentin or periodontium (21), however, in contrast, the characterization of dental epithelial stem cells has proven to be more elusive because they are hard to grow in vitro. To date, it has proved difficult to maintain primary enamel organ epithelial (EOE) cells in cultures for prolonged periods with the primary phenotype (22). In fact, although the establishment of a primary culture system for porcine ameloblasts has been previously reported, the approach involved the transformation and immortalization of EOE cells with the transforming genes of simian virus 40 (23). Recently, a system for multiplication without transformation has been reported, using mouse ameloblasts as the cell source (24). We have tried to develop a strategy using only culture techniques to grow EOE cells to generate enamel however there are two obstacles that must be overcome in order to successfully grow EOE cells. The first obstacle is that porcine epithelial cell growth is disrupted if contaminated with dental mesenchymal cells, due to the high proliferation capacity of the mesenchymal cells $(22,25)$. Secondly, expansion of porcine dental epithelial cells in vitro has been problematic due to their tendency to terminally differentiate after only a few passages (25). In order to overcome these obstacles, we combined two techniques: a non-serum culture system and a 3T3-J2 feeder layer system, derived from a mouse teratoma (Fig. 1). Den Besten and colleagues had previously reported that a non-serum selective medium (LHC-9) enables the growth of only EOE cells while the accompanying mesenchymal cells are killed (22), however one disadvantage of this non-serum selective medium is the low growth potential of the EOE cells. We were encouraged by reports of the adaptation of a feeder layer technique for the culture of keratinocytes which enabled the long-term culture of these cells during which time they retained an epithelial phenotype $(26,27)$ and we considered that the disadvantages of a non-serum medium could be overcome using the feeder layer technique. Then, to determine whether the feeder layer system would be effective for EOE cells, enamel organs were harvested from the third molar teeth of a 6-month-old-pig (Fig. 2). Since enamel organs are connected to dental follicles, primary cultures of the EOE cells appeared to be contaminated with dental follicle cells, as we expected. The EOE cells were isolated from the mesenchymal cells using the non-serum medium, and then seeded onto a 3T3-J2 feeder layer for sequential subcultures (Fig. 3a). The EOE cell colonies grew with time in culture (Fig. $3 b$ ) and were able to be maintained for at least 4 passages. The subcultured EOE cells from both the primary culture and after 4 passages expressed amelogenin, ameloblastin, MMP-20 (28), KLK4 (29), and enamelin (30), but not alkaline phosphatase (Fig. 4a). No obvious changes in the expression of ameloblast-related genes were detected during long-term culture. Furthermore, expression of amelogenin in subcultured EOE cells was shown by fluorescence immunocytochemistry (Fig. 4b), and Western blotting revealed secretion of amelogenin by the EOE cells into the culture medium.

By using 3T3-J2 cells as a feeder layer, we have successfully overcome the limitations of odontogenic epithelial cell culture. The passaged cells express the ameloblast-specific 
markers amelogenin, ameloblastin and enamelysin, but not enamelin. The culturing of epithelial cells on a feeder layer of 3T3 cells has proven to be a major advance, because this provides an environment that considerably improves cell proliferation $(26,27)$. The development and characterization of these cultured epithelial cells is also useful for further studies of enamel tissue engineering.

\section{Enamel tissue engineering}

Developing a technique to manipulate EOE cells is a significant advance towards enamel replacement and therefore we attempted to develop a strategy to generate enamel based on subcultured EOE cells using tissue engineering technology. To examine the enamel-forming capability of subcultured EOE cells, we made use of techniques we had developed previously by transplanting cells onto a biodegradable scaffold in vivo (31-33). Newly generated tooth tissue was formed by tissue engineering techniques requiring an interaction between dental mesenchymal cells and EOE cells (31). As previously described, the constructs were prepared by isolating fresh dental pulp cells from the third molars of pigs during the early stage of crown formation (32). Dental pulp cells were first plated on top of a scaffold and then subcultured EOE cells were seeded directly on top of the pulp cells. In the primary control group, the scaffolds were seeded with subcultured EOE cells alone. In the secondary control group, oral epithelial cells obtained from the oral mucosa were subcultured (34) and seeded in combination with fresh dental pulp cells onto the scaffolds. We had previously determined that the use of a collagen sponge was superior to that of polyglycolic acid fiber mesh (Nipro Corporation, Japan), and so collagen sponges were used as scaffolds for the dental cells (35). Interestingly, histological analysis showed subcultured EOE cells gave rise to ectopic cartilage tissue under the primary control group conditions (36), while the implants grown under the conditions of the secondary control group not only generated enamel but also cartilage. Amelogenin gene splice products have the ability to enhance the transcription factor sox9 $(37,38)$, therefore, amelogenin secreted from the cultured EOE cells may induce chondrocytes from the mesenchymal stem cells in the surrounding omentum of the rat host. Four weeks after transplantation of EOE cells combined with dental pulp cells in scaffolds, several phenomena related to amelogenesis were distinguished in the implants. In the most mature structures, enamel was readily found in the implants (Fig. 5a). Furthermore, amelogenin immunoreactivity was detected in tall columnar epithelial cells on the surface of the dentin or enamel, indicating that the tissue-engineered enamel contains well-developed ameloblasts (Fig. 5b). Together, these results indicate that the subcultured EOE cells have the potential to generate enamel. Interestingly, enamel formation was always observed after dentin was formed in the implants. On the other hand, when subcultured EOE cells were combined with subcultured dental pulp cells, enamel-dentin complexes were not observed in any of the implants. In addition, the production of enamel by EOE cells was observed within 4 weeks of transplantation of the constructs (33), which was markedly earlier than that observed with constructs established from non-cultured EOE cells which generated enamel at 15-25 weeks after transplantation $(3,31,39)$. Enamel production may have been facilitated in our culture model because EOE cells were maintained at an undifferentiated stage in the ameloblast-lineage cell phenotype by the 3T3 feeder layer. Our culture model provides a promising step towards a new therapy for reforming enamel but further study is needed on 
how to combine the newly-generated enamel with the original dental dentin or enamel in the tooth. As EOE cells disappear in adult teeth after tooth eruption we also need to discover new cell sources to advance this technology in the clinical setting.

\section{New cell sources for enamel tissue engineering}

\subsection{Epithelial cell rest of Malassez}

The epithelium surrounding the teeth after eruption is anatomically classified into 4 types of epithelium; the oral gingival epithelium, the oral sulcular epithelium, the junctional epithelium, and the epithelial cell rests of Malassez (ERM). The epithelium, except for ERM, covers the surface, while ERM, developmental residues of Hertwig's epithelial root sheath (HERS), are embedded within the PDL tissue. Since ERM are a direct lineage from HERS, derived from the enamel organ through the cervical loop structures, we hypothesized that ERM retain their original ability to secrete a matrix conducive to generating enamel in a fashion similar to the enamel organ in the crown formation stage. Previously, there was a report supporting our hypothesis showing that removal of stem cells from their natural milieu may change their differentiation properties. A well-studied example of this phenomenon involves hematopoietic stem cells. Furthermore, we recently reported that the epithelial cells from HERS can differentiate into ameloblasts and produce enamel-dentin complexes when combined with non-cultured dental pulp cells in the core of the dental pulp (40).

The epithelial cell rests of Malassez in the periodontium were thought to be completely quiescent $(41,42)$, however it is now known that ERM can be induced to differentiate into cementoblasts $(43,44)$ with disruption of Patched, the hedgehog receptor, leading to shorter roots (45). Moreover, it has been suggested that ERM might prevent resorption of the root surface (46) and although ERM are generally in the G0 phase of the cell cycle, ERM can be stimulated to proliferate in response to injury (47). ERM also have the potential to differentiate in two different directions: squamous metaplasia and formation of cystic lesions, and ameloblastic differentiation during the formation of odontogenic tumors $(48,49)$, suggesting that ERM have a mitotic activity $(50,51)$. In fact, when the ERM cells are cultured in vitro, they actively proliferate but there have been no reports of the in vivo behavior of subcultured ERM cells. To investigate the potential of ERM cells for generating enamel, we established a cell culture system for ERM cells in order to preserve as many of the original cellular characteristics as possible, and then designed a study to examine the tissue-forming capability of ERM cells(53).

Firstly, we examined the presence of ERM cells in deciduous incisor teeth. In histological sections, clusters of aggregated cells were easily recognized in the PDL of porcine deciduous incisor teeth. The clustered cells expressed cytokeratin-14, an epithelial cell marker. Interestingly, immunolabeling for amelogenin was not observed in any of the epithelial cell clusters.

We then prepared three types of epithelial cells (ERM, EOE cells, and oral gingival epithelial cells) and PDL cells from the same mandible of a 6-month-old pig. The deciduous incisor teeth were removed from the mandible and then the PDLs were removed from the middle one-third of the incisor tooth roots. The PDLs were placed in culture dishes and then ERM cells and PDL cells migrated from the explants. Before the cells reached confluence, the serum containing growth medium was replaced with a non-serum epithelial cell-selective 
medium. After replacement with the non-serum medium, the PDL cells were detached from the culture dish and the ERM cells subsequently survived. The growth of the ERM cells in non-serum medium was quite slow, similar to the behavior of EOE cells. ERM cells were then subcultured on 3T3-J2 feeder cell layers with complete-MEM medium, the same reagents used in the culture of EOE cells (36) and oral gingival epithelial cells (52). The ERM cells colonies increased with time and became confluent after 2 weeks. Subcultured ERM cells were passaged and this was repeated ten times with feeder cell layers. All passaged cells showed the typical polygonal-shaped epithelial morphology. Interestingly, when ERM were subcultured on collagen type I coated without a feeder cell layer, the ERM cells displayed an extended morphology.

We compared the cell characteristics of the subcultured ERM, EOE cells, and oral gingival epithelial cells, produced using the same feeder cell layer technique. No appreciable differences were found in any of the cell morphologies (Fig. 6a-c), and all cell populations were able to grow on the feeder cell layer at similar growth rates. Gene expression patterns of the subcultured ERM were then compared to EOE cells using ameloblast-related markers. Both ERM and EOE cells expressed ameloblastin and tuftelin, while EOE cells alone expressed amelogenin, MMP20, and KLK4. None of the cell populations expressed enamelin. The expression patterns of the ameloblast-related genes in ERM were inconsistent with those in EOE cells. In particular, subcultured ERM did not show expression of amelogenin as well as the histological observation of the root surface of deciduous teeth. These results suggest ERM would not have the potential to grow enamel.

The possibility that ERM cells can differentiate into ameloblasts was examined in vitro using a co-culture model with dental pulp cells. Presumably, dental pulp has the potential to induce dental epithelial cells into ameloblasts (40). Surprisingly, although no immunoreactivity for amelogenin was observed in the ERM cells alone over a 4-week culture period (Fig. 7a-c), when ERM cells were co-cultured with dental pulp cells, both cytokeratin-14 and amelogenin were clearly positive (Fig. 7d-f). Since there was now a possibility of ERM differentiating into ameloblasts, the capacity of subcultured ERM cells to produce enamel was examined by transplanting subcultured ERM cells, seeded onto scaffolds, into the omentum of athymic rats. Histological analysis showed that all implants displayed the appropriate stages of amelogenesis from initiation to maturation. At 8 weeks post-transplantation, enamel-dentin complex structures were recognized in the implants (Fig. 8a). At high magnification, the width of the enamel was approximately $100 \mu \mathrm{m}$ (Fig. 8b). Amelogenin expression was also detected in the region of the tall columnar cells. These results demonstrate that subcultured ERM have the potential to differentiate into ameloblasts and generate enamel in vivo, suggesting that ERM could be a new cell source for tissue engineering techniques investigating enamel replacement in the future (53).

Generally, tissue-specific stem cells are thought to be activated by a repair and regeneration process and they are maintained in a quiescent state until they are required to act on behalf of the tissue. The normal behavior of stem cells is strictly governed by the cellular microenvironment. ERM are able to grow in vitro and become free of the influence of the PDL cells. It could be that ERM have the characteristics of epithelial stem/progenitor cells.

\subsection{Bone marrow stroma cells}

It has been known that bone marrow contains stem cells that can give rise to various types 
of epithelial cells. One experimental study was designed to determine whether bone marrow cells could differentiate into ameloblasts (55) and the success of this study provides a new cell source for enamel tissue engineering. Basically, bone marrow contains two types of stem cell - hematopoietic and mesenchymal. The ability of hematopoietic stem cells to give rise to epithelial cells has already been shown for tissues such as skin, lung, and liver. However, although bone marrow cells have the potential to differentiate into dental mesenchymal cells (56), their ability to differentiate into ameloblasts has never been examined. Bone marrow cells were collected from tibias and femurs of CD1 mice and isolated using c-kit, a cytokine tyrosine kinase receptor expressed by hematopoietic progenitor cells. Dental epithelium was dissociated into single cells and the single cell suspension was mixed with the bone marrow cell suspension to form a pellet. The pellet was re-associated with dental mesenchyme obtained from the tooth germ at embryonic day 14. After 20 days of culture, a tooth crown was generated from the constructs. The c-kit-positive bone marrow cells were present in the inner dental epithelium and expressed both amelogenin and ameloblastin, as shown by in situ hybridization (53). This was the first report to show that bone marrow cells can differentiate into ameloblasts. However, so far, no studies have shown that bone marrow cells alone, without dental epithelial cells, can differentiate into ameloblasts.

\subsection{Oral keratinocytes}

At an early stage the embryonic oral epithelium provides the instructive signals for tooth initiation and development. These signals are received by the mesenchymal cells, which are then primed to become odontogenic and in turn act as a source of reciprocal signals back to the epithelium. In mice, dental epithelium prior to embryonic day 12.5 has these instructions, and then at this stage, the ability shifts to the dental mesenchyme from the epithelium. Of note, non-dental embryonic epithelium can differentiate into dental epithelium when there is interaction with odontogenic mesenchyme (55). Thus it is possible that non-dental epithelial cells may be a new cell source for enamel tissue engineering technology.

Of particular interest is whether post-natal non-dental oral epithelium can differentiate into ameloblasts to generate enamel. A recent study (57) designed to investigate this question obtained oral epithelium from the palatal epithelium of ICR mice at post-natal day 1 and the palatal epithelial cells were separated from the mesenchyme. Mandibular molar teeth from embryonic day 12.5-16.5 were isolated and dental mesenchyme was separated from the dental epithelium. The dissociated epithelial cells were combined with the mandibular molar mesenchyme for re-association. The epithelium covered the entire surface of the molar mesenchyme. After 2 days of culture, the re-associations were transplanted under the kidney capsule of an adult mouse as the host. Samples were obtained 14 days after transplantation and analyzed by histology. The re-association of palatal epithelium with dental mesenchyme formed tooth germs associated with enamel-dentin complexes (58). Therefore palatal mucosal epithelium, not only from embryos but also from newborn mice, has the potential to differentiate into ameloblasts and then generate enamel. However, the palatal epithelia of mice more than 2 days of age could not differentiate into ameloblasts. As we prefer to use older cells for enamel tissue engineering, clearly further studies are needed to resolve this problem for the clinical setting. 


\section{Conclusions and future directions}

For a long time metal and resin have been investigated as potential sources to replace enamel. In our laboratory, we are focusing on producing enamel by tissue engineering methods as these techniques are believed to be an extremely powerful approach to replacing enamel. This goal has remained elusive until recently when we finally identified a new tissue engineering method to generate enamel using a specialized enamel organ culture technique and transplantation system. However, two problems still remain to be solved before this technique can be used for clinical applications. Firstly, there is still no method to combine the tissue-engineered enamel with the injured enamel of the original teeth. Secondly, we still cannot control the shape and size of the tissue-engineered enamel. If these two above issues could be addressed then a method to reform the injured enamel on teeth could be developed. The authors thank Dr. Haward Green (Harvard Medical School) for critical reading of the manuscript.

\section{Acknowledgments}

This work was supported by Grants-in-Aid for Scientific Research from the Ministry of Education, Science, Sports and Culture, Japan. We thank all laboratory staff who helped with this work. The authors thank Dr. Haward Green (Harvard Medical School) for critical reading of the manuscript.

\section{References}

1. Bergenholtz G. Inflammatory response of the dental pulp to bacterial irritation. J Endod. 1981 Mar;7(3):100-104.

2. Smith AJ. Pulpal responses to caries and dental repair. Caries Res. 2002 Jul-Aug;36(4):223-232.

3. Young CS, Terada S, Vacanti JP, Honda M, Bartlett JD, Yelick PC. Tissue engineering of complex tooth structures on biodegradable polymer scaffolds. J Dent Res. 2002 Oct;81(10):695-700.

4. Miletich I, Sharpe PT. Normal and abnormal dental development. Hum Mol Genet. 2003 Apr 1;12 Spec No 1:R69-73.

5. Thesleff I, Sharpe P. Signalling networks regulating dental development. Mech Dev. 1997 Oct;67(2):111-123.

6. Gibson CW, Yuan ZA, Hall B, Longenecker G, Chen E, Thyagarajan T, et al. Amelogenin-deficient mice display an amelogenesis imperfecta phenotype. J Biol Chem. 2001 Aug 24;276(34):31871-31875.

7. Hatakeyama J, Sreenath T, Hatakeyama Y, Thyagarajan T, Shum L, Gibson CW, et al. The receptor activator of nuclear factor-kappa B ligand-mediated osteoclastogenic pathway is elevated in amelogenin-null mice. J Biol Chem. 2003 Sep 12;278(37):35743-35748.

8. Gibson CW, Kulkarni AB, Wright JT. The use of animal models to explore amelogenin variants in amelogenesis imperfecta. Cells Tissues Organs. 2005;181(3-4):196-201. 
9. Li Y, Suggs C, Wright JT, Yuan ZA, Aragon M, Fong H, et al. Partial rescue of the amelogenin null dental enamel phenotype. J Biol Chem. 2008 May 30;283(22):15056-15062.

10. Du C, Falini G, Fermani S, Abbott C, Moradian-Oldak J. Supramolecular assembly of amelogenin nanospheres into birefringent microribbons. Science. 2005 Mar 4;307(5714):1450-1454.

11. Cerny R, Slaby I, Hammarstrom L, Wurtz T. A novel gene expressed in rat ameloblasts codes for proteins with cell binding domains. J Bone Miner Res. 1996 Jul;11(7):883-891.

12. Krebsbach PH, Lee SK, Matsuki Y, Kozak CA, Yamada KM, Yamada Y. Full-length sequence, localization, and chromosomal mapping of ameloblastin. A novel tooth-specific gene. J Biol Chem. 1996 Feb 23;271(8):4431-4435.

13. Fong CD, Cerny R, Hammarstrom L, Slaby I. Sequential expression of an amelin gene in mesenchymal and epithelial cells during odontogenesis in rats. Eur J Oral Sci. 1998 Jan;106 Suppl 1:324-330.

14. Fukumoto S, Kiba T, Hall B, Iehara N, Nakamura T, Longenecker G, et al. Ameloblastin is a cell adhesion molecule required for maintaining the differentiation state of ameloblasts. J Cell Biol. 2004 Dec 6;167(5):973-983.

15. Paine ML, Wang HJ, Luo W, Krebsbach PH, Snead ML. A transgenic animal model resembling amelogenesis imperfecta related to ameloblastin overexpression. J Biol Chem. 2003 May 23;278(21):19447-19452.

16. Hu JC, Hu Y, Smith CE, McKee MD, Wright JT, Yamakoshi Y, et al. Enamel defects and ameloblast-specific expression in Enam knock-out/lacz knock-in mice. J Biol Chem. 2008 Apr 18;283(16):10858-10871.

17. Honda M, Yada T, Ueda M, Kimata K. Cartilage formation by cultured chondrocytes in a new scaffold made of poly(L-lactide-epsilon-caprolactone) sponge. J Oral Maxillofac Surg. 2000 Jul;58(7):767-775.

18. Honda MJ, Yada T, Ueda M, Kimata K. Cartilage formation by serial passaged cultured chondrocytes in a new scaffold: hybrid 75:25 poly(L-lactide-epsilon-caprolactone) sponge. J Oral Maxillofac Surg. 2004 Dec;62(12):1510-1516.

19. Gronthos S, Mankani M, Brahim J, Robey PG, Shi S. Postnatal human dental pulp stem cells (DPSCs) in vitro and in vivo. Proc Natl Acad Sci $U S A .2000$ Dec 5;97(25):13625-13630.

20. Miura M, Gronthos S, Zhao M, Lu B, Fisher LW, Robey PG, et al. SHED: stem cells from human exfoliated deciduous teeth. Proc Natl Acad Sci U S A. 2003 May 13;100(10):5807-5812.

21. Seo BM, Miura M, Gronthos S, Bartold PM, Batouli S, Brahim J, et al. Investigation of multipotent postnatal stem cells from human periodontal ligament. Lancet. $2004 \mathrm{Jul}$ 10-16;364(9429):149-155.

22. Den Besten PK, Mathews CH, Gao C, Li W. Primary culture and characterization of enamel organ epithelial cells. Connect Tissue Res. 1998;38(1-4):3-8; discussion 35-41.

23. DenBesten PK, Gao C, Li W, Mathews CH, Gruenert DC. Development and characterization of an SV40 immortalized porcine ameloblast-like cell line. Eur J Oral Sci. 1999 Aug;107(4):276-281.

24. Nakata A, Kameda T, Nagai H, Ikegami K, Duan Y, Terada K, et al. Establishment and characterization of a spontaneously immortalized mouse ameloblast-lineage cell line. Biochem Biophys Res Commun. 2003 Sep 5;308(4):834-839. 
25. Kukita A, Harada H, Kukita T, Inai T, Matsuhashi S, Kurisu K. Primary and secondary culture of rat ameloblasts in serum-free medium. Calcif Tissue Int. 1992 Nov;51(5):393-398.

26. Rheinwald JG, Green H. Serial cultivation of strains of human epidermal keratinocytes: the formation of keratinizing colonies from single cells. Cell. 1975 Nov;6(3):331-343.

27. Rheinwald JG, Green H. Formation of a keratinizing epithelium in culture by a cloned cell line derived from a teratoma. Cell. 1975 Nov;6(3):317-330.

28. Fukae M, Tanabe T, Uchida T, Lee SK, Ryu OH, Murakami C, et al. Enamelysin (matrix metalloproteinase-20): localization in the developing tooth and effects of $\mathrm{pH}$ and calcium on amelogenin hydrolysis. J Dent Res. 1998 Aug;77(8):1580-1588.

29. Hu JC, Ryu OH, Chen JJ, Uchida T, Wakida K, Murakami C, et al. Localization of EMSP1 expression during tooth formation and cloning of mouse cDNA. J Dent Res. 2000 Jan;79(1):70-76.

30. $\mathrm{Hu}$ JC, Zhang CH, Yang Y, Karrman-Mardh C, Forsman-Semb K, Simmer JP. Cloning and characterization of the mouse and human enamelin genes. J Dent Res. 2001 Mar;80(3):898-902.

31. Honda MJ, Sumita Y, Kagami H, Ueda M. Histological and immunohistochemical studies of tissue engineered odontogenesis. Arch Histol Cytol. 2005 Jun;68(2):89-101.

32. Honda MJ, Tsuchiya S, Sumita Y, Sagara H, Ueda M. The sequential seeding of epithelial and mesenchymal cells for tissue-engineered tooth regeneration. Biomaterials. 2007 Feb;28(4):680-689.

33. Honda MJ, Shinohara Y, Hata KI, Ueda M. Subcultured odontogenic epithelial cells in combination with dental mesenchymal cells produce enamel-dentin-like complex structures. Cell Transplant. 2007;16(8):833-847.

34. Hata K, Kagami H, Ueda M, Torii S, Matsuyama M. The characteristics of cultured mucosal cell sheet as a material for grafting; comparison with cultured epidermal cell sheet. Ann Plast Surg. 1995 May;34(5):530-538.

35. Sumita Y, Honda MJ, Ohara T, Tsuchiya S, Sagara H, Kagami H, et al. Performance of collagen sponge as a 3-D scaffold for tooth-tissue engineering. Biomaterials. 2006 Jun;27(17):3238-3248.

36. Honda MJ, Shimodaira T, Ogaeri T, Shinohara Y, Hata K, Ueda M. A novel culture system for porcine odontogenic epithelial cells using a feeder layer. Arch Oral Biol. 2006 Apr;51(4):282-290.

37. Veis A, Tompkins K, Alvares K, Wei K, Wang L, Wang XS, et al. Specific amelogenin gene splice products have signaling effects on cells in culture and in implants in vivo. $J$ Biol Chem. 2000 Dec 29;275(52):41263-41272.

38. Nebgen DR, Inoue H, Sabsay B, Wei K, Ho CS, Veis A. Identification of the chondrogenic-inducing activity from bovine dentin (bCIA) as a low-molecular-mass amelogenin polypeptide. J Dent Res. 1999 Sep;78(9):1484-1494.

39. Honda MJ, Shinohara Y, Sumita Y, Tonomura A, Kagami H, Ueda M. Shear stress facilitates tissue-engineered odontogenesis. Bone. 2006 Jul;39(1):125-133.

40. Sumita Y, Tsuchiya S, Asahina I, Kagami H, Honda MJ. The location and characteristics of two populations of dental pulp cells affect tooth development. Eur J Oral Sci. 2009 Apr;117(2):113-121. 
41. Grupe HE, Jr., ten Cate AR, Zander HA. A histochemical and radiobiological study of in vitro and in vivo human epithelial cell rest proliferation. Arch Oral Biol. 1967 Dec;12(12):1321-1329.

42. Valderhaug JP, Nylen MU. Function of epithelial rests as suggested by their ultrastructure. J Periodontal Res. 1966;1:69-78.

43. Thomas HF. Root formation. Int J Dev Biol. 1995 Feb;39(1):231-237.

44. Bosshardt DD, Schroeder HE. Cementogenesis reviewed: a comparison between human premolars and rodent molars. Anat Rec. 1996 Jun;245(2):267-292.

45. Nakatomi M, Morita I, Eto K, Ota MS. Sonic hedgehog signaling is important in tooth root development. J Dent Res. 2006 May;85(5):427-431.

46. Loe H, Waerhaug J. Experimental replantation of teeth in dogs and monkeys. Arch Oral Biol. 1961 Apr;3:176-184.

47. Talic NF, Evans CA, Daniel JC, Zaki AE. Proliferation of epithelial rests of Malassez during experimental tooth movement. Am J Orthod Dentofacial Orthop. 2003 May;123(5):527-533.

48. Buchner A, Sciubba JJ. Peripheral epithelial odontogenic tumors: a review. Oral Surg Oral Med Oral Pathol. 1987 Jun;63(6):688-697.

49. Hamamoto Y, Hamamoto N, Nakajima T, Ozawa H. Morphological changes of epithelial rests of Malassez in rat molars induced by local administration of N-methylnitrosourea. Arch Oral Biol. 1998 Nov;43(11):899-906.

50. McCulloch CA, Melcher AH. Continuous labelling of the periodontal ligament of mice. J Periodontal Res. 1983 May;18(3):231-241.

51. Trowbridge HO, Shibata F. Mitotic activity in epithelial rests of Malassez. Periodontics. 1967 May-Jun;5(3):109-112.

52. Hata K, Ueda M. Fabrication of cultured epithelium using oral mucosal cells and its clinical applications. Hum Cell. 1996 Mar;9(1):91-96.

53. Hu B, Unda F, Bopp-Kuchler S, Jimenez L, Wang XJ, Haikel Y, et al. Bone marrow cells can give rise to ameloblast-like cells. J Dent Res. 2006 May;85(5):416-421.

54. Shinmura Y, Tsuchiya S, Hata KI, Honda MJ. Quiescent epithelial cell rests of Malassez can differentiate into ameloblast-like cells. J Cell Physiol. 2008; 217: 728-738.

55. Ohazama A, Modino SA, Miletich I, Sharpe PT. Stem-cell-based tissue engineering of murine teeth. J Dent Res. 2004 Jul;83(7):518-522.

56. Mina M, Kollar EJ. The induction of odontogenesis in non-dental mesenchyme combined with early murine mandibular arch epithelium. Arch Oral Biol. 1987;32(2):123-127.

57. Nakagawa E, Itoh T, Yoshie H, Satokata I. Odontogenic potential of post-natal oral mucosal epithelium. J Dent Res. 2009 Mar;88(3):219-223. 
Figure legends

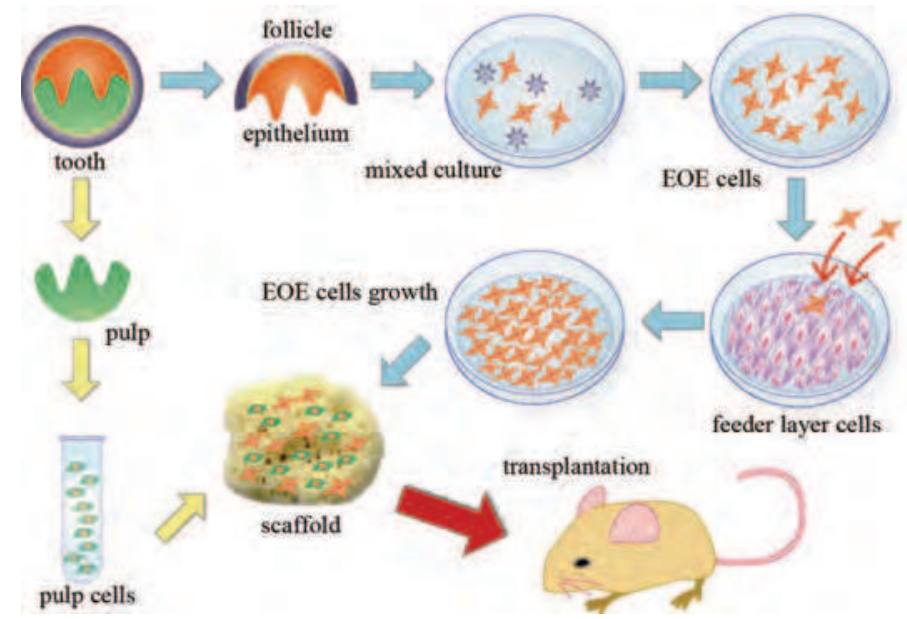

Fig. 1. A strategy for tissue-engineered enamel.

First, enamel organ epithelium was isolated from dental pulp and dental follicles. Enamel organ epithelial (EOE) cells were isolated from mesenchymal cells in culture using a non-serum medium. EOE cells were subcultured on the 3T3-J2 feeder layer cells. Thereafter, subcultured EOE cells were combined with primary dental pulp cells and the constructs were transplanted into the omentum of immunodeficient rats.

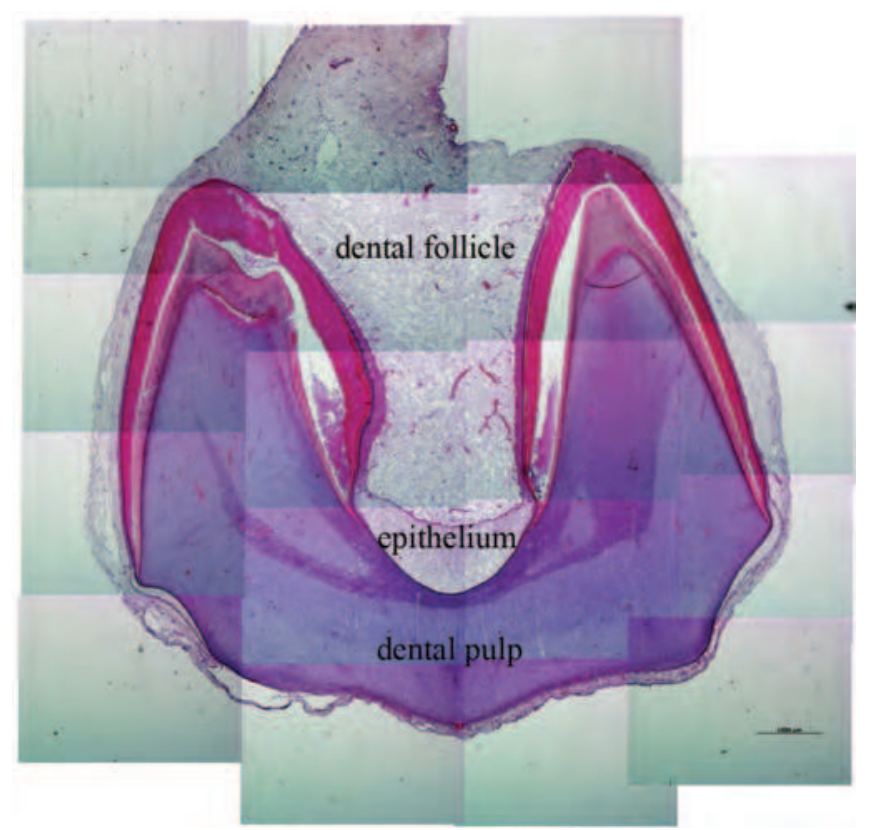

Fig. 2. A third molar tooth stained with hematoxylin and eosin ( $\mathrm{H} \& \mathrm{E})$. Tooth crown 
formation is partly achieved. Enamel organ epithelium is connected with the dental follicle.

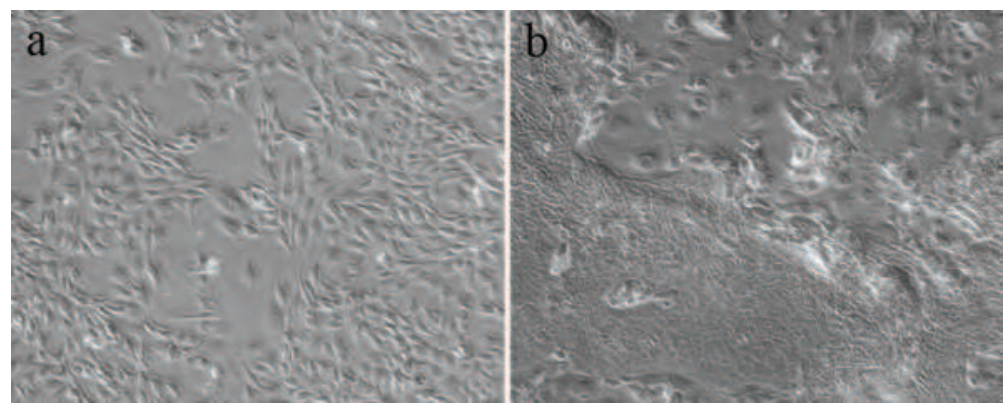

Fig. 3. a: Phase contrast micrograph of 3T3-J2 feeder layer cells.

b: The isolated enamel organ epithelial (EOE) cells were seeded onto the 3T3-J2 feeder layer and the EOE cell colonies grew with time in culture.

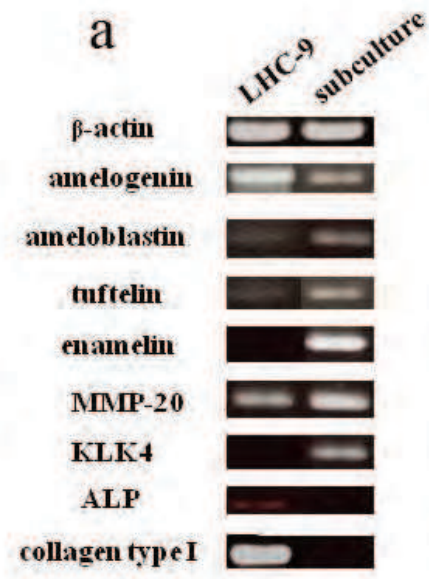




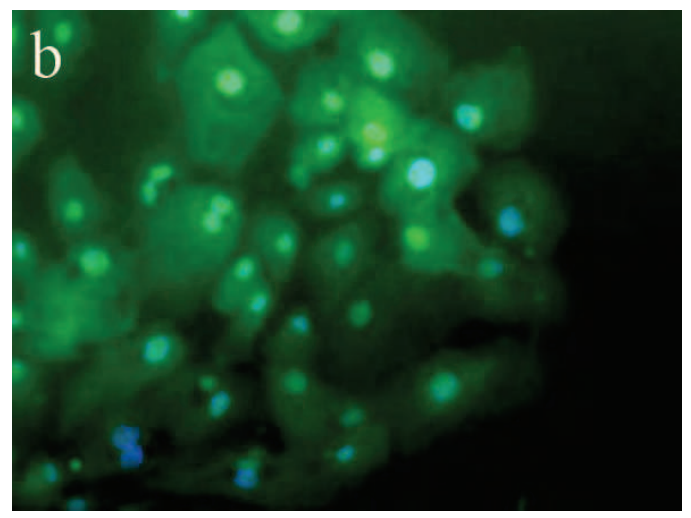

Fig. 4. a: The subcultured enamel organ epithelial (EOE) cells from both the primary culture and after 4 passages expressed amelogenin, ameloblastin, MMP-20, kallikrein-4 (KLK4), and enamelin, but not alkaline phosphatase.

b: Fluorescence immunocytochemistry showing the expression of amelogenin in subcultured EOE cells at passage 2 .

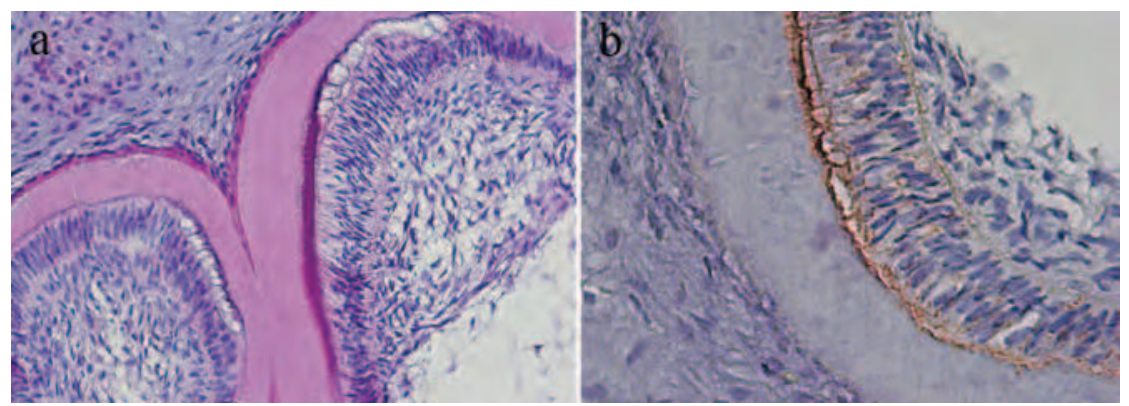

Fig. 5. a: Four weeks after transplantation, enamel was readily found in the implants. b: Amelogenin immunoreactivity was detected in tall columnar epithelial cells on the surface of the dentin or enamel.

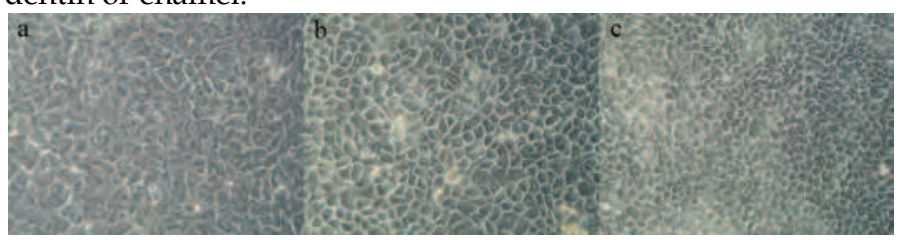

Fig. 6. a-c: There was no appreciable difference in cell morphology among epithelial cell rests of Malassez (ERM) (a), enamel organ epithelial (EOE) cells (b), and oral gingival epithelial cells (c). 

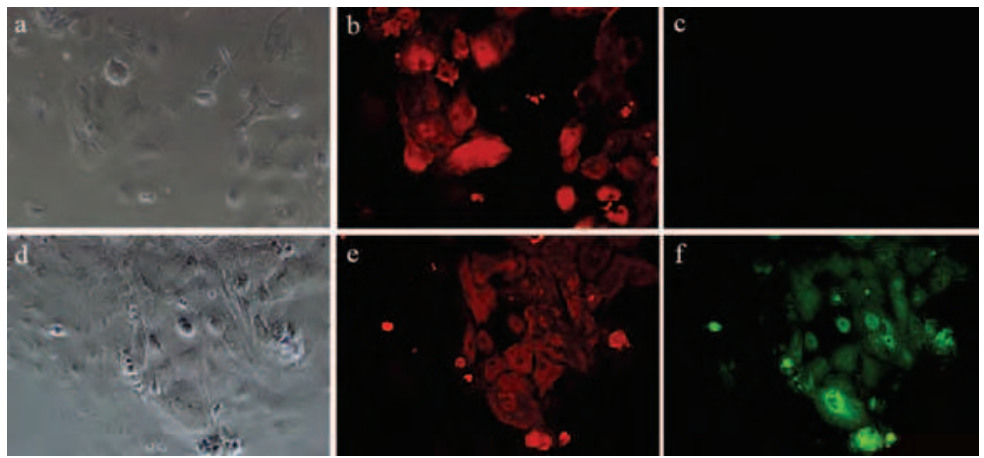

Fig. 7. Cytokeratin14 (CK14) and amelogenin expressions in vitro

a-c: When ERM were co-cultured with 3T3-J2 cells (a), immunofluorescence showed that ERM were positive for cytokeratin-14 (b) and were negative for amelogenin (c).

d-f: When ERM were co-cultured with primary dental pulp cells (d), both cytokeratin-14 (e) and amelogenin (f) were clearly positive.

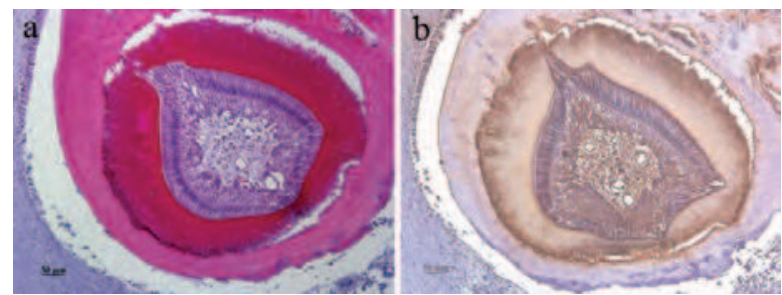

Fig. 8. a: At 8 weeks post-transplantation, enamel-dentin complex structures were recognized in the implants.

b: At high magnification view, the width of the enamel was approximately $100 \mu \mathrm{m}$. 


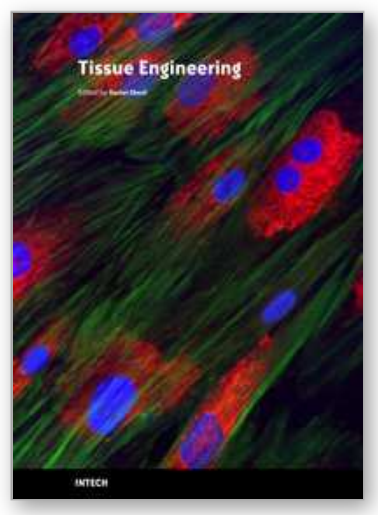

\author{
Tissue Engineering \\ Edited by Daniel Eberli
}

ISBN 978-953-307-079-7

Hard cover, 524 pages

Publisher InTech

Published online 01, March, 2010

Published in print edition March, 2010

The Tissue Engineering approach has major advantages over traditional organ transplantation and circumvents the problem of organ shortage. Tissues that closely match the patient's needs can be reconstructed from readily available biopsies and subsequently be implanted with minimal or no immunogenicity. This eventually conquers several limitations encountered in tissue transplantation approaches. This book serves as a good starting point for anyone interested in the application of Tissue Engineering. It offers a colorful mix of topics, which explain the obstacles and possible solutions for TE applications.

\title{
How to reference
}

In order to correctly reference this scholarly work, feel free to copy and paste the following:

Masaki J. Honda and Ken-ichiro Hata (2010). Enamel Tissue Engineering, Tissue Engineering, Daniel Eberli (Ed.), ISBN: 978-953-307-079-7, InTech, Available from: http://www.intechopen.com/books/tissueengineering/enamel-tissue-engineering

\section{INTECH}

open science | open minds

\section{InTech Europe}

University Campus STeP Ri

Slavka Krautzeka 83/A

51000 Rijeka, Croatia

Phone: +385 (51) 770447

Fax: +385 (51) 686166

www.intechopen.com

\section{InTech China}

Unit 405, Office Block, Hotel Equatorial Shanghai

No.65, Yan An Road (West), Shanghai, 200040, China

中国上海市延安西路65号上海国际贵都大饭店办公楼405单元

Phone: +86-21-62489820

Fax: +86-21-62489821 
(C) 2010 The Author(s). Licensee IntechOpen. This chapter is distributed under the terms of the Creative Commons Attribution-NonCommercialShareAlike-3.0 License, which permits use, distribution and reproduction for non-commercial purposes, provided the original is properly cited and derivative works building on this content are distributed under the same license. 